\title{
The Effect of a Change in Perception of Length Distribution of a Population on Maturity-at-age, Weight-at-age and Spawning Stock Biomass
}

\author{
M. J. Morgan \\ Dept. of Fisheries and Oceans, P. O. Box 5667 \\ St. John's, Newfoundland, Canada A1C 5X1
}

\begin{abstract}
The calculation of proportion mature-at-age and mean weight-at-age from length stratified sampling are dependent on the length distribution of the population. The Dept. of Fisheries and Oceans in St. John's, Newfoundland changed its survey bottom trawl in the autumn of 1995. Comparative fishing experiments between the old and new fishing gears showed that the new gear (Campelen) caught more small fish of most species than the old (Engel) gear. Conversions of the Engel time series to Campelen equivalents results in an increase in the number of small fish in the population. This paper examines the effect of this change on maturity-at-age, mean weight-at-age and spawning stock biomass (SSB) for American plaice (Hippoglossoides platessoides). The shift in the perceived length frequency distribution of the population results in an increase in age at $50 \%$ maturity (the fish appear to be maturing later) and a decrease in mean weight-at-age. Spawning stock biomass calculated from these parameters is higher for the Campelen equivalent data because of the increased abundance at age. Trends in maturity-at-age, mean weight-at-age and SSB over the time period are generally the same for the Engel and Campelen equivalent data. Constructing a time series, which consists of unconverted Engel data followed by Campelen data, can be misleading. The change in estimated maturity and weight-at-age, and SSB has implications for both biological studies and the setting of reference levels.
\end{abstract}

Key words: American plaice, biomass, fishing gear, length distribution, weight

\section{Introduction}

Proportion mature-at-age, mean weight-at-age and spawning stock biomass are important parameters in the estimation of population growth rate, potential yield of a fishery and management reference levels for the precautionary approach. Shifts in these parameters will result in changes in the subsequent estimates (Welch and Foucher, 1988; Serchuk et al., MS 1997; Sinclair, MS 1997). These parameters could change as a result of actual variation in the population or because of a change in sampling.

In the autumn of 1995 , the Department of Fisheries and Oceans in the Newfoundland Region changed its survey gear from an Engel 145 High Lift otter trawl to a Campelen 1800 shrimp trawl (see McCallum and Walsh, MS 1996, for details of these gear types). Comparative fishing studies showed that the Campelen trawl was more efficient at capturing small fish of most species than the
Engel trawl (Warren et al., MS 1997). Length based conversion factors were developed from these trials. When these conversion factors are applied to the Engel time series for American plaice (Hippoglossoides platessoides) there is an increase in the estimated abundance of fish less than $40 \mathrm{~cm}$, with the magnitude of the increase varying with fish length (Morgan et al., MS 1998).

The perceived length frequency of a population will affect the calculation of proportion mature-atage (Morgan and Hoenig, 1997) and mean weightat-age when length stratified sampling designs are used. This is because a given age group straddles several length classes and the proportion mature and weight increase with length. The change in estimated length frequency of the population resulting from the conversion of Engel data to Campelen equivalent data should produce changes in the estimates of proportion mature and mean weight-at-age and SSB derived from these data. This paper examines the difference between these 
estimates for Engel and Campelen equivalent data for American plaice in NAFO Div. 3LNO.

\section{Materials and Methods}

Data used in this study were collected during the Department of Fisheries and Oceans spring research vessel surveys of NAFO Divisions 3LNO from 1985 to 1995 using the Engel 145 High Lift otter trawl. In addition, data for spring 1996 and 1997 in NAFO Divisions 3LNO using the Campelen 1800 shrimp trawl were examined. All surveys were conducted using a stratified random survey design (Doubleday, 1981). During these surveys, length frequency data were collected from every successful fishing set. Ages were determined from otoliths collected according to a length stratified sampling scheme. For fish that were sampled for age, maturity stages were determined at sea according to the criteria of Templeman et al. (1978). Starting in 1990, fish weights were also collected at sea from the fish sampled for age determination.

Data from 1985 to 1995 were converted to Campelen equivalents as outlined in Morgan et al. (MS 1998). The conversion equation was:

$$
N_{C F x}=C F_{x} \cdot N_{E x}
$$

where: $N_{C F x}=$ the converted number at length $x$

$N_{E x}=$ number at length $x$ from the Engel data

$C F_{x}=$ the conversion factor for length $x$

for $x \leq 23 \mathrm{~cm} C F_{x}=10.02$

for $24 \mathrm{~cm} \leq x<40 \mathrm{~cm} \ln \left(C F_{x}\right)=39.958+0.358$ $[x-41 \ln (x)]$

for $\quad x \geq 40 \mathrm{~cm} C F_{x}=1$

The original numbers at length and the converted numbers at length were used to produce population numbers at length using swept area calculations. Population numbers at age were also produced from the original and converted numbers at length. Proportion mature-at-age, mean weightat-age and SSB were calculated using the converted and unconverted data, as well as the 1996 and 1997 survey data.

Estimated proportion mature-at-age for each sex was calculated as:

$$
M_{a}=\frac{\sum_{j=1}^{J} P(j) P(a \mid j) P(m \mid a, j)}{\sum_{j=1}^{J} P(j) P(a \mid j)}
$$

where: $P(j) \quad=$ estimated fraction of the catch that is length category $j$.

$P(a \mid j) \quad=$ proportion of the sampled fish in length category $j$ which are age $a$.

$P(m \mid a, j)=$ proportion of the sampled fish at age $a$ which are mature in the length category $j$.

$J \quad=$ number of length classes.

Age at 50\% maturity was estimated for both data sets using a logistic model with a logit link function and a binomial error (SAS, 1989).

Mean weight-at-age for each sex was calculated as:

$$
\bar{W}_{a}=\frac{\sum_{j=1}^{J}\left(\sum_{i=1}^{I} P(j) w_{i a j}\left(\frac{1}{n_{j}}\right)\right)}{\sum_{j=1}^{J} P(j) P(a \mid j)}
$$

where: $W_{i a j} \quad=$ weight of fish $i$ at age $a$ and length category $j$

$n_{j} \quad=$ number of fish sampled for age determination at length category $j$

and the other symbols are as defined above.

Spawning stock biomass was calculated for the original and converted series as:

$$
\sum_{a=1}^{A} N_{a} M_{a} \bar{W}_{a}
$$

where $N_{a}$ is the estimated population number at age $a$ and $A$ is the number of age groups. Only females were included in the estimate of SSB.

\section{Results}

Estimated proportion mature-at-age for males and females tended to be lower for the converted data than for the original Engel data (Fig. 1 and 2). Trends over time were very similar for the original and converted time series for both sexes. Trends in 

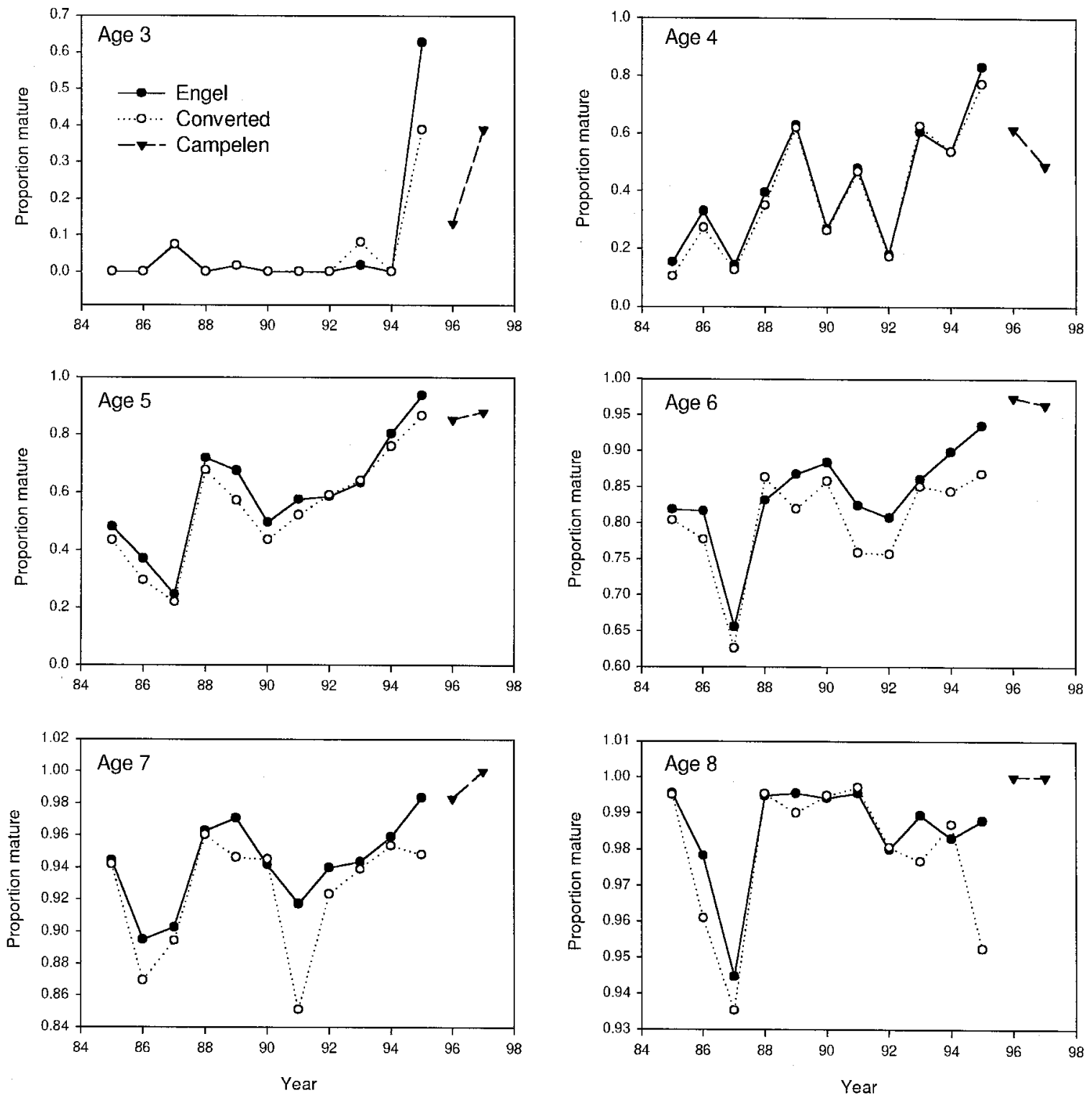

Fig. 1. Proportion mature-at-age for males ages 3 to 8 for the Engel (solid circles), Campelen equivalent (open circles) and Campelen (solid triangles) data.

maturity between 1995 (last Engel survey) and 1996 (first Campelen survey) appear similar in direction whether the original series or the converted data series is continued with the Campelen data, although the magnitude of the change is not always the same (e.g. males age 8, Fig. 1).

The lower estimated proportion mature-at-age for the converted series results in a higher age at $50 \%$ maturity in most years for that time series compared to the original data (Fig. 3). Again, trends over the time period are very similar for the original and converted series. Continuing the unconverted series with the Campelen series that began in 1996 would not change the perception of any trend in age at 50\% maturity between 1995 and 1996 compared to extending the converted series.

Mean weight-at-age was lower for the converted data than for the original Engel data (Fig. 4 and 5). Trends over time were similar for the two series, although there was a greater difference between the two series in the last two years for males (Fig. 4). There were several instances (e.g. 

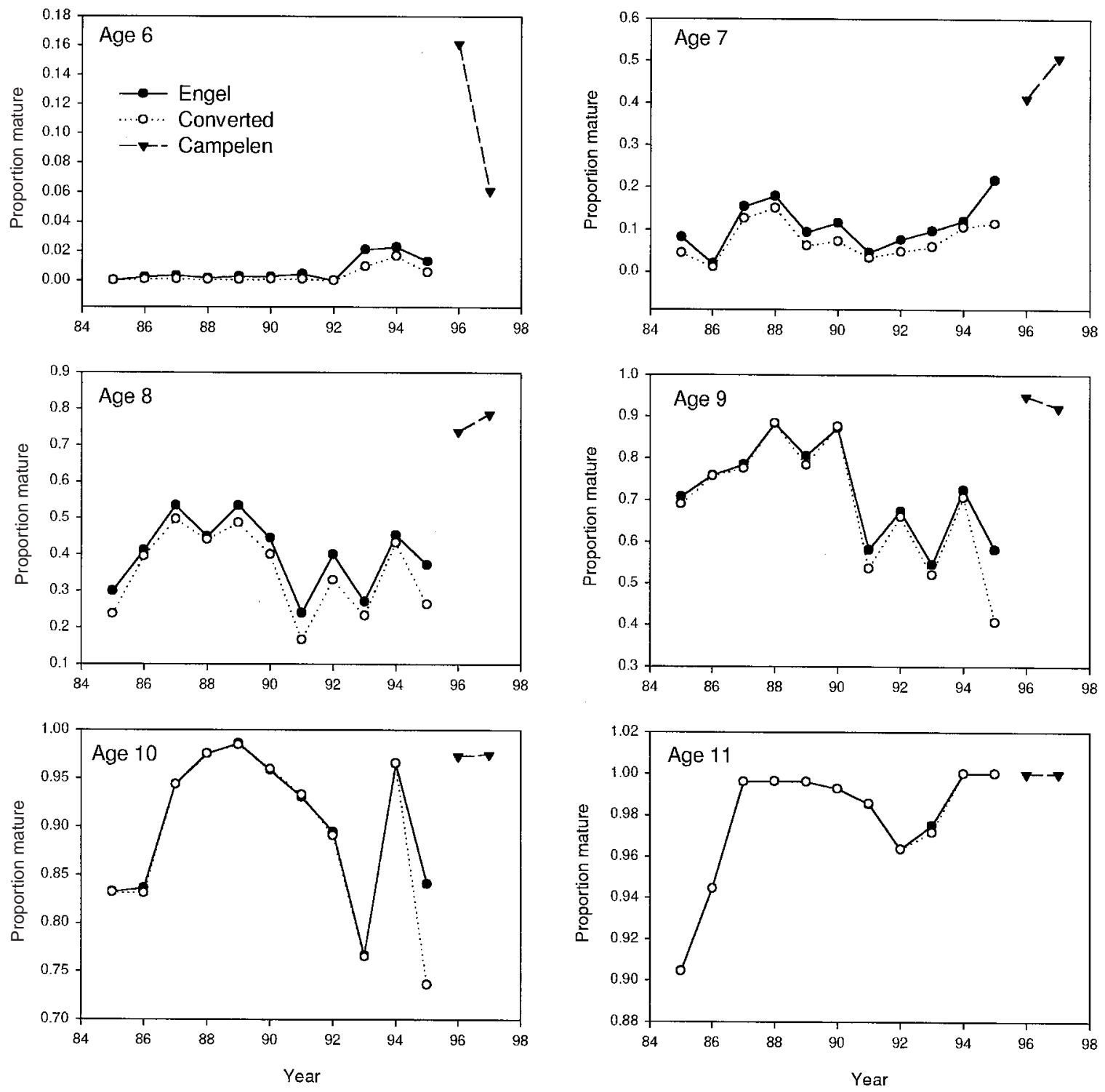

Fig. 2. Proportion mature-at-age for females ages 6 to 11 for the Engel (solid circles), Campelen equivalent (open circles) and Campelen (solid triangles) data.

female age 6, Fig. 5) where extending the unconverted Engel series with the new Campelen series would result in a change in perception of trends. Specifically, the converted series shows an increase in mean weight-at-age between 1995 and 1996 while the unconverted series shows a decrease in mean weight-at-age when joined to the Campelen series.

Differences in proportion mature and mean weight-at-age were greatest for intermediate ages (Fig. 6). For proportion mature-at-age these were ages 3 to 7 for males and 5 to 9 for females. For mean weight-at-age these were ages 3 to 9 for males and 4 to 9 for females.

Spawning stock biomass showed the same trend over time for both the converted and original data (Fig. 7). The converted time series was 43 to $60 \%$ higher than the original series over the 1990 to 1995 period, a difference of 5000 to 80000 tons.

\section{Discussion}

Proportion mature-at-age and mean weight-atage were generally lower when calculated using the 

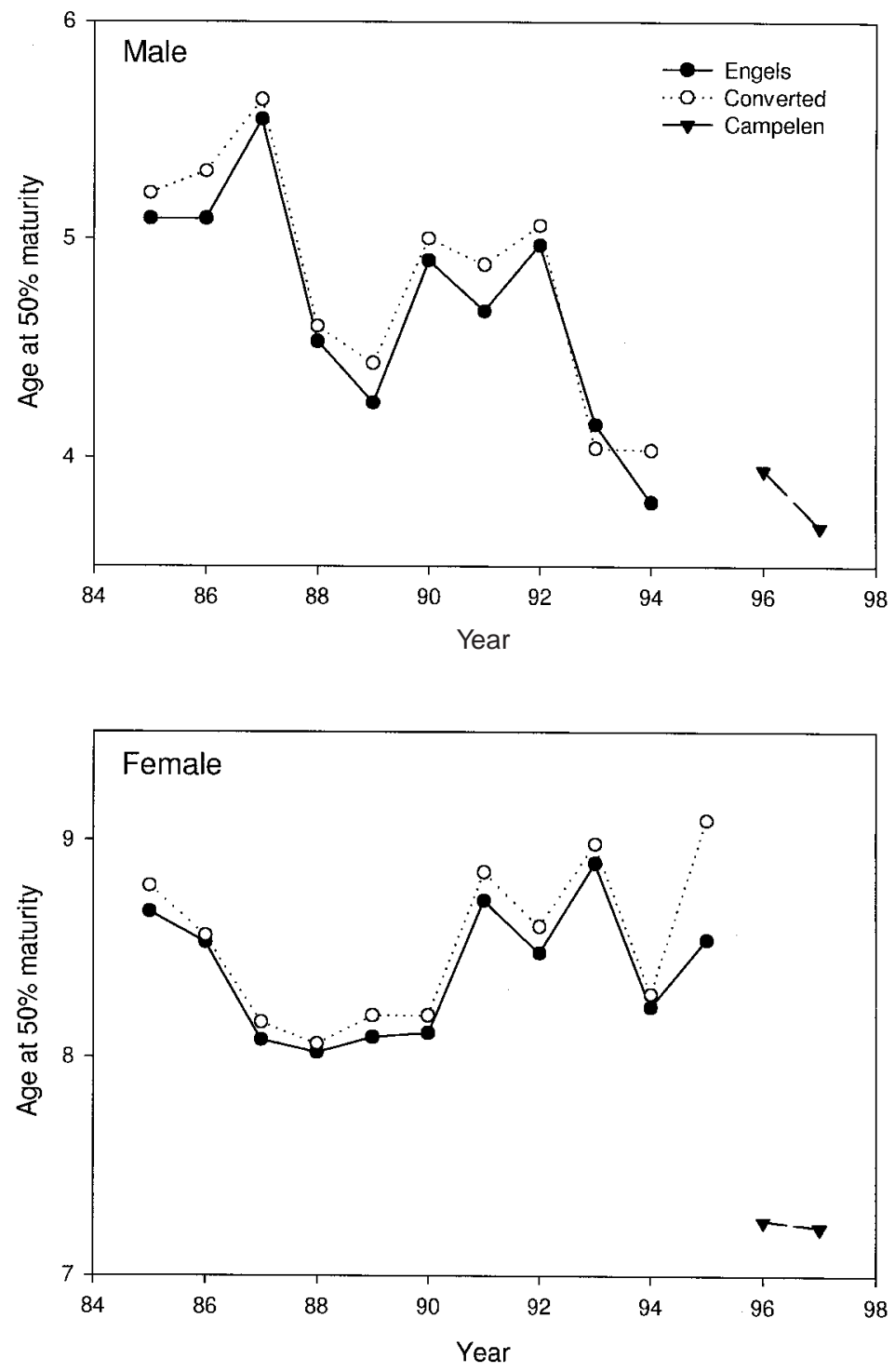

Fig. 3. Age at 50\% maturity for males and females for the Engel (solid circles), Campelen equivalent (open circles) and Campelen (solid triangles) data. No result is shown for males for 1995 as there was not a significant fit of the model to the data.

converted time series than when using the original Engel data. The length-based conversion has a greater effect at smaller sizes and increases the proportion of smaller fish at a given age. These smaller fish weigh less and are less likely to be mature, resulting in a decrease in mean weight and proportion mature-at-age. This effect was greatest at intermediate age-classes. The oldest ages (10+) are composed mainly of fish greater than $40 \mathrm{~cm}$ and therefore have no change in length frequency distribution when the conversion is applied (i.e. CF $=1.0$ ). The youngest ages (4 and younger) span fewer length classes and many of the length classes are $<23 \mathrm{~cm}$ to which a constant conversion factor is applied, again resulting in little change in the length frequency distribution.

There was a 40 to $60 \%$ difference between the SSB calculated from the converted data and from the original Engel data. Although the proportion 

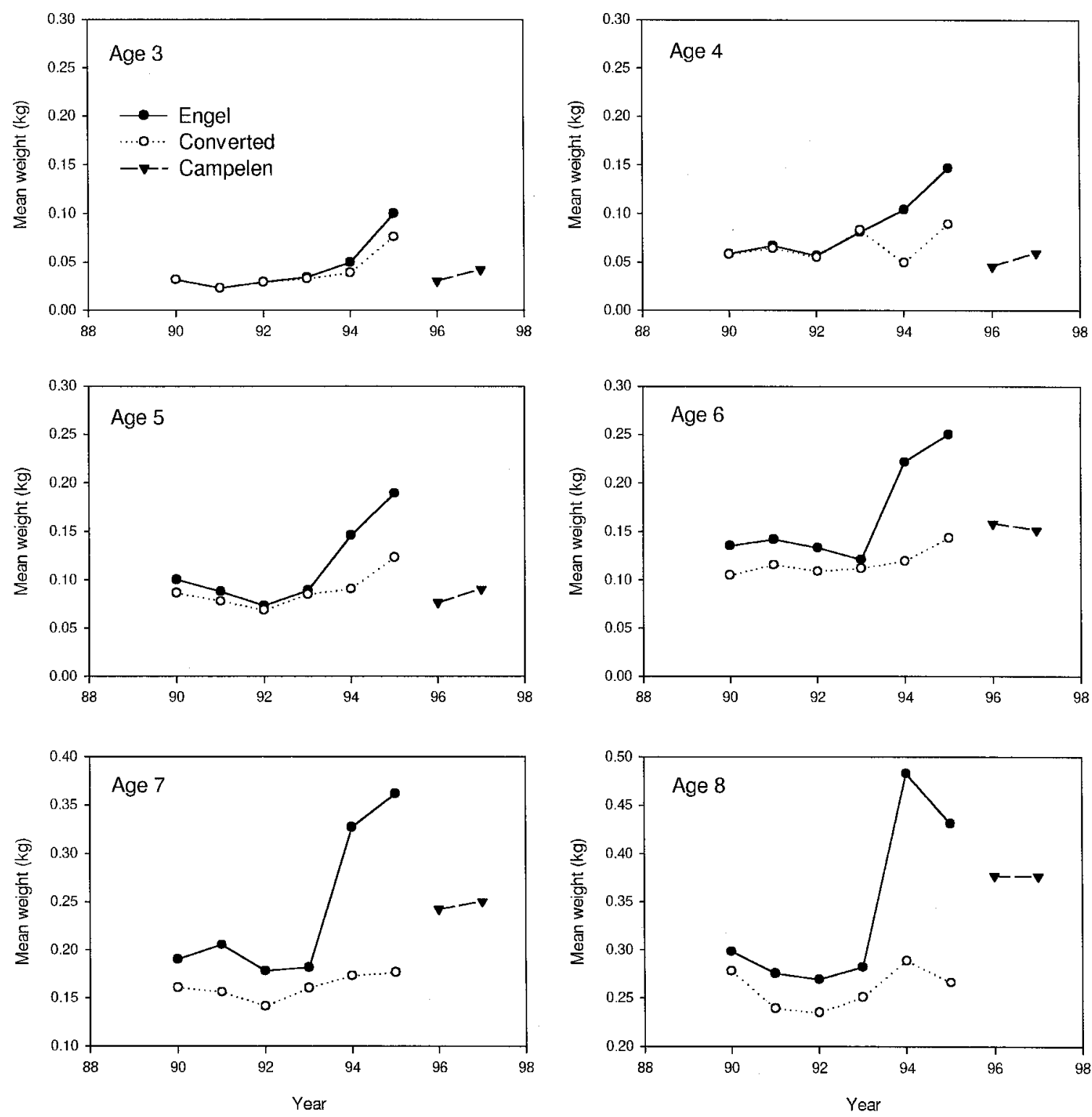

Fig. 4. Mean weight-at-age for males ages 3 to 8 for the Engel (solid circles), Campelen equivalent (open circles) and Campelen (solid triangles) data.

mature and mean weight-at-age were generally lower for the Campelen equivalent series, the abundance at age was higher and this resulted in an increase in SSB. Trends in proportion mature-atage would also affect the magnitude of the difference in SSB between the two series as the proportion of the SSB made up of fish in the ageclasses most affected by the conversion changed.

The trends in proportion mature and mean weight-at-age and SSB were generally similar over the time period for both series. However, if the unconverted time series from 1985-95 is extended by the Campelen series beginning in 1996, trends can appear to be different than if the converted series is joined with the new Campelen series. For any studies spanning this time period the series should either be treated separately or the converted data used with the new Campelen series. This conclusion would apply to all species for which conversion factors are available since comparative fishing trials indicated an increased number at smaller lengths for all of the species studied (Warren, 1996; Warren et al., MS 1997). This result 

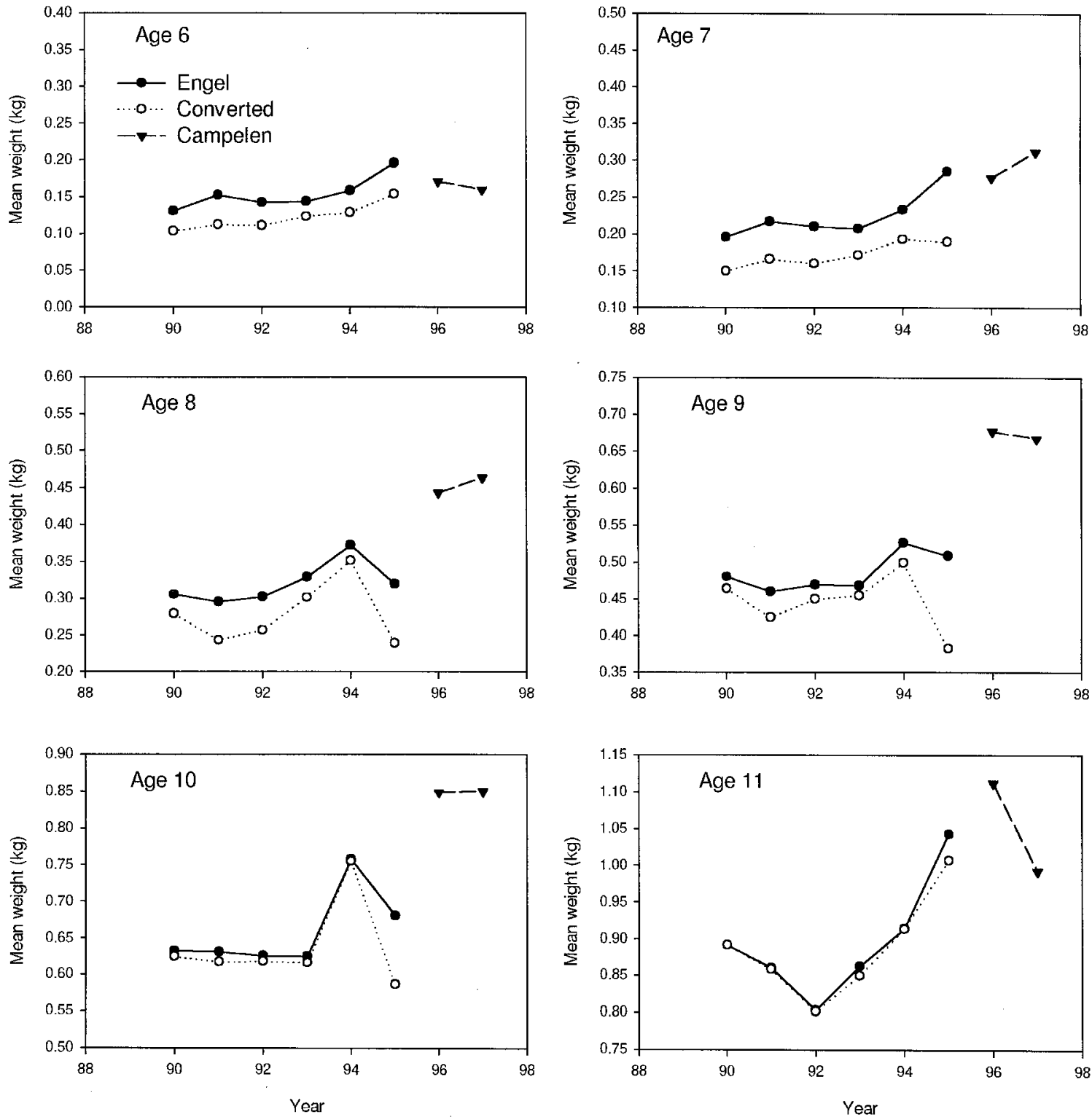

Fig. 5. Mean weight-at-age for females ages 6 to 11 for the Engel (solid circles), Campelen equivalent (open circles) and Campelen (solid triangles) data.

has implications not only for studies of maturation and growth, but also for the setting and monitoring of reference levels for the precautionary approach since reference levels will be affected by the level of SSB, proportion mature and mean weight-at-age (Serchuk et al., MS 1997; Sinclair, MS 1997).

The conversion does not make the Engel time series fully 'Campelen equivalent'. The accuracy of the estimated conversion factors was considered to be good in the mid-length range of the data but poor at the smallest and largest sizes (Warren et al., MS 1997). Because of this a constant conversion factor has been applied to the smallest $(<23 \mathrm{~cm})$ and largest $(>40 \mathrm{~cm}$ ) American plaice (Morgan et al., MS 1998). This could have a large effect since each age-class is composed of fish of a wide range of sizes, (sometimes spanning as much as $30 \mathrm{~cm}$ ) and many ages have fish that are below $23 \mathrm{~cm}$ as well as fish that are above $40 \mathrm{~cm}$. This may be at least part of the cause of the large difference between estimates of proportion mature and mean 

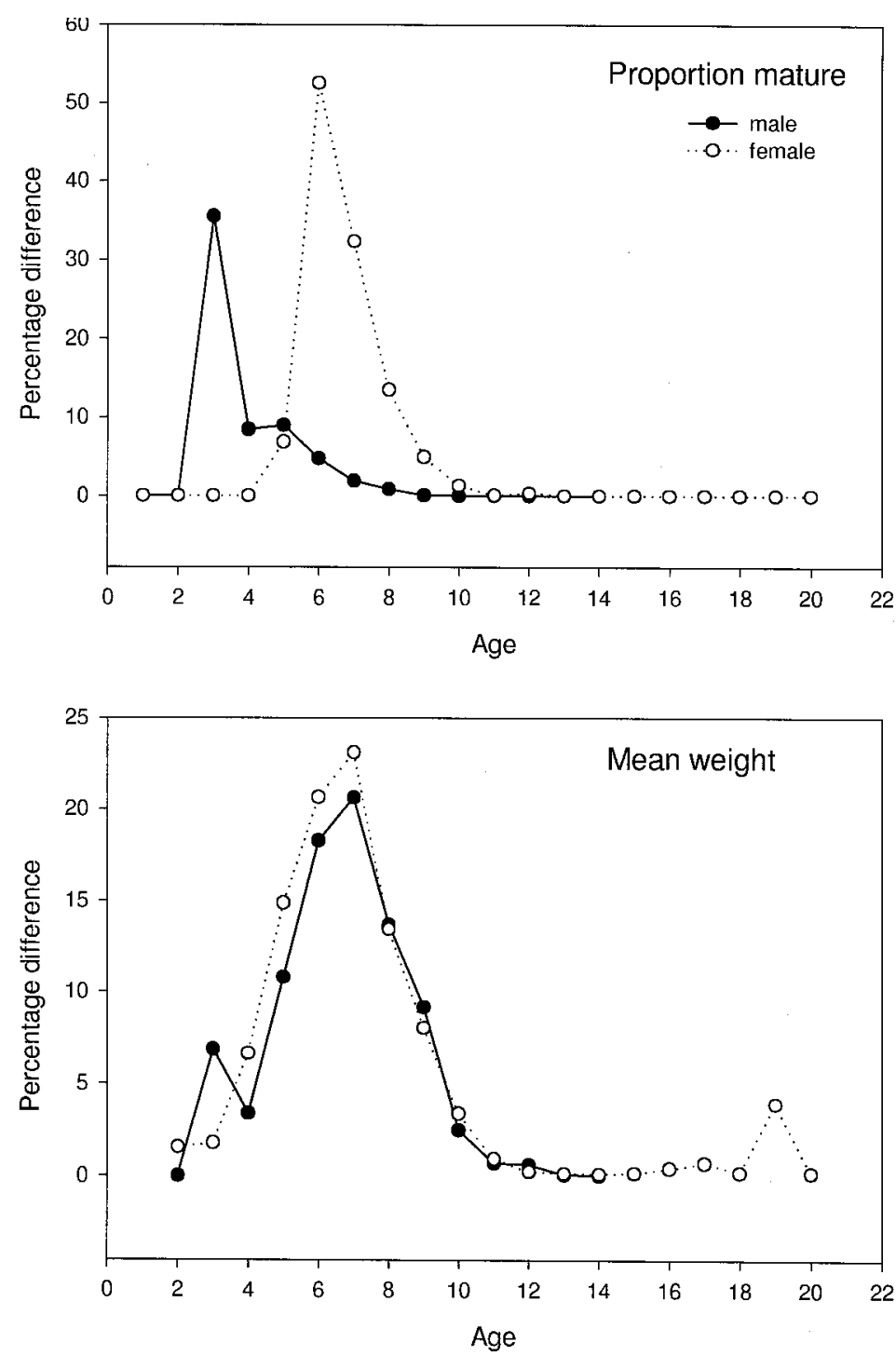

Fig. 6. Mean percentage difference by age between Engel and Campelen equivalent data for males (solid circles) and females (open circles) for proportion mature-at-age and mean weight-at-age.

weight-at-age for the converted data in 1995 and the Campelen data in 1996. Interpretations of trends in these parameters over this time period must be cautious.

The differences detected in this study highlight the fact that our estimates of proportion mature and mean weight-at-age and SSB do not reflect the true values of these parameters. Rather our estimates are subject to the selectivity of our sampling gear and will change when this selectivity changes.

\section{Acknowledgements}

I thank all the scientific and ships crews involved in the collection of these data. Dave Orr converted the length frequencies and set details. Two anonymous reviewers gave helpful comments on the manuscript. 

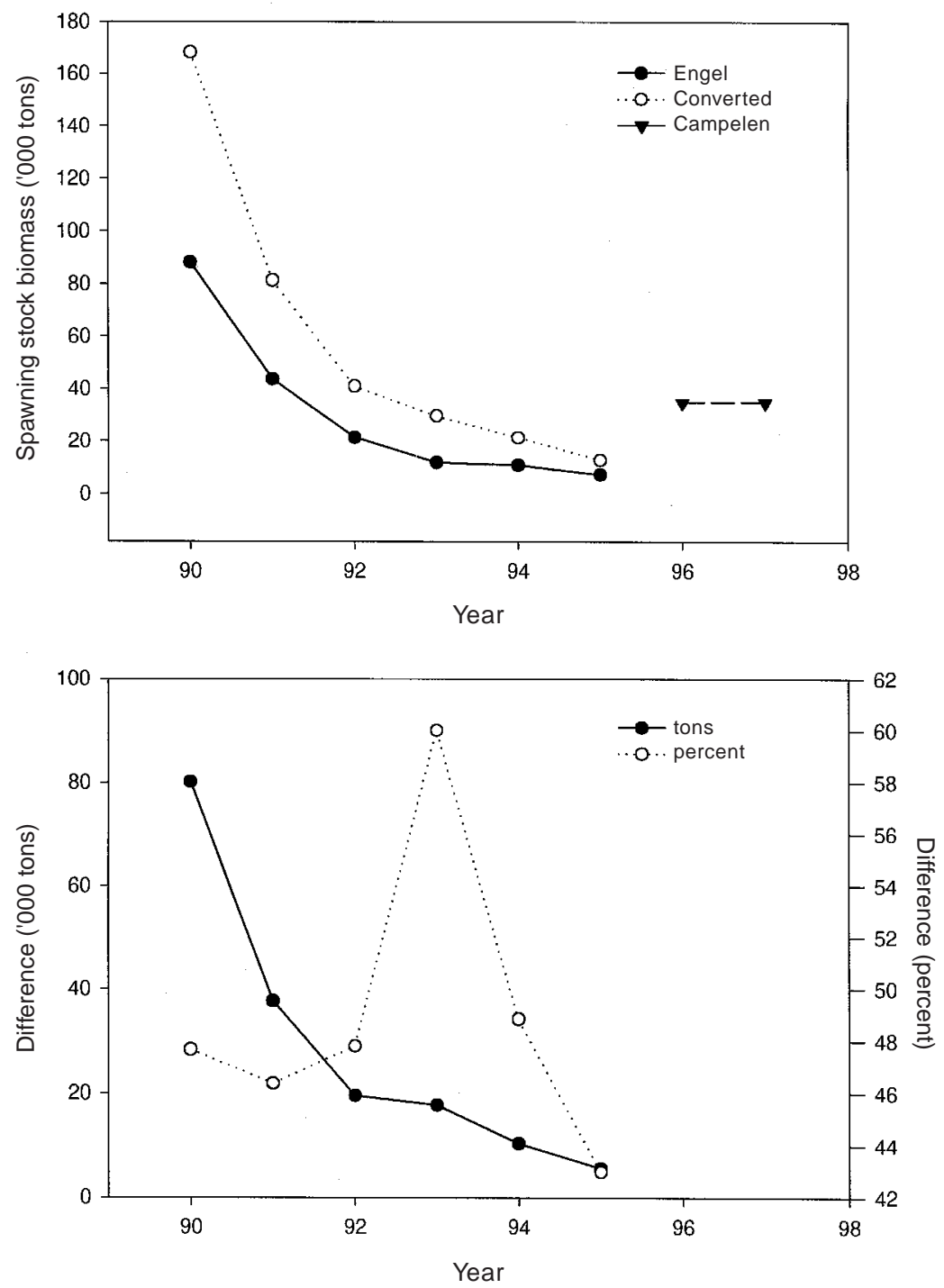

Fig. 7. Spawning stock biomass ('000 tons) for Engel (solid circles), Campelen equivalent (open circles) and Campelen (solid triangles) data (top panel). The bottom panel shows the difference in spawning stock biomass in thousands of tons (solid circles) and percent (open circles) between Engel and Campelen equivalent data.

\section{References}

DOUBLEDAY, W. G. 1981. Manual on groundfish surveys in the Northwest Atlantic. NAFO Sci. Coun. Studies, 2: $55 \mathrm{p}$.

MCALluM, B. R. and S. J. WALSH. MS 1996. Groundfish survey trawls used at the Northwest Atlantic Fisheries Centre, 1971 to present. NAFO SCR Doc., No. 50, Serial No. N2726, 18 p.

MORGAN, M. J., and J. M. HOENIG. 1997. Estimating maturity-at-age from length stratified sampling. $J$.
Northw. Atl. Fish. Sci., 21: 51-63.

MORGAN, M. J., W. B. BRODIE, W. R. BOWERING, D. MADDOCK PARSONS, and D. C. ORR. MS 1998. Results of data conversions for American plaice in Div. 3LNO from comparative fishing trials between the Engel otter trawl and the Campelen 1800 shrimp trawl. NAFO SCR Doc., No. 70, Serial No. N3062, $10 \mathrm{p}$.

SAS INSTITUTE INC. 1989. SAS/STAT User's Guide. Cary, NC. SAS Institute Inc.

SERCHUK, F., D. RIVARD, J. CASEY, and R. MAYO. 
MS 1997. Report of the ad hoc working group of the NAFO Scientific Council on the precautionary approach. NAFO SCS Doc., No. 12, Serial No. N2911, 61 p.

SINCLAIR, A. MS 1997. Biological reference points relevant to a precautionary approach to fisheries management: an example for Southern Gulf of St. Lawrence cod. NAFO SCR Doc., No. 77, Serial No. N2914, 16 p.

TEMPLEMAN, W., V. M. HODDER, and R. WELLS. 1978. Sexual maturity and spawning in haddock Melanogrammus aeglefinus of the southern Grand Bank. ICNAF Res. Bull., 13: 53-65.

WARREN, W. G. 1996. Report on the comparative fishing trial between the Gadus Atlantica and Teleost. NAFO Sci. Coun. Studies, 29: 81-90.

WARREN, W., W. BRODIE, D. STANSBURY, S. WALSH, J. MORGAN, and D. ORR. MS 1997. Analysis of the 1996 comparative fishing trial between the Alfred Needler with the Engel 145 trawl and the Wilfred Templeman with the Campelen 1800 trawl. NAFO SCR Doc., No. 68, Serial No. N2902, $12 \mathrm{p}$.

WELCH, D. W., and R. P. FOUCHER. 1988. A maximum likelihood methodology for estimating length-atmaturity with application to Pacific cod (Gadus macrocephalus) population dynamics. Can. J. Fish. Aquat. Sci., 45: 333-343. 